\title{
Minute Times Nanogram per Milliliter per Kilogram per Meter Squared
}

National Cancer Institute

\section{Source}

National Cancer Institute. Minute Times Nanogram per Milliliter per Kilogram per Meter

Squared. NCI Thesaurus. Code C111268.

Minutes times nanograms per milliliter, divided by kilograms per meter squared. 